Proceedings of the Institution of
Civil Engineers
Energy 163
August 2010 Issue EN3
Pages $93-105$
doi: $10.1680 /$ ener.2010.163.3.93
Paper 900024
Received 03/06/2009
Accepted 26/10/2009
Keywords:
hydraulics \& hydrodynamics/
maritime engineering/renewable
energy

Miles Willis, lan Masters, Sara Thomas, Rebecca Galle, Jo Loman and Andy Cook Marine Energy Research Group, School of Engineering, Swansea University, Wales, UK Reza Ahmadian, Roger Falconer, Binliang Lin and Guanghai Gao Institute of Environment and Sustainability, Cardiff University, Wales, UK

Mark Cross, Nick Croft, Alison Williams and Medzid Muhasilovic an Horsfall and Rob Fidler

\title{
Tidal turbine deployment in the Bristol Channel: a case study
}

M. Willis, I. Masters, S. Thomas, R. Gallie, J. Loman, A. Cook, R. Ahmadian, R. Falconer, B. Lin, G. Gao, M. Cross, N. Croft, A. Williams, M. Muhasilovic, I. Horsfall, R. Fidler, C. Wooldridge, I. Fryett, P. Evans, T. O'Doherty, D. O'Doherty and A. Mason-Jones

The renewable energy route map for Wales outlines ambitious targets for $50 \%$ renewables by 2025 . The Welsh coast, subject to tidal ranges of the order of $13 \mathrm{~m}$ and tidal flows in excess of $3 \mathrm{~m} / \mathrm{s}$, is thus in an ideal position to significantly contribute to these targets. Tidal stream energy is an emerging energy sector and a relatively small number of devices are at various stages of development in Wales. However, before such demonstration devices or arrays can be applied at a larger scale, a number of consents and permissions must be obtained to ensure safe and environmentally responsible deployment. This paper describes the multidisciplinary work that has been undertaken on an area of ocean that could be used for the deployment of a tidal stream turbine. The paper aims to put the scientific work undertaken into the context of device deployment in a complex marine environment and to provide an overview of the surveying and modelling required for the deployment of a single demonstration device off the Welsh coast. The Bristol Channel was chosen as a case study because of its high tidal flows and proximity to national grid connections and support infrastructure. This paper provides an overview of the research carried out during the project; the details of each discipline will be provided in individual papers by the respective subject authors.

\section{INTRODUCTION}

Wales consumes 33 TWh of electricity per year, traditionally from coal-based power stations, but now increasingly from onshore and offshore wind, hydroelectric, biomass and photovoltaic sources. The Welsh Assembly government (WAG) has recently launched the renewable energy route map for Wales (WAG, 2008), which sets out to not only significantly reduce demand but also to supply all electricity from renewable sources by 2025. It is expected that marine energy will contribute up to half of this electricity production. A number of innovative marine energy schemes have been proposed in Wales, including tidal barrages, lagoons, coastally attached impoundments, wave and tidal stream devices.

Where moving bodies of water meet landmasses, channels, estuaries or underwater features, energy is concentrated and can cause significant tidal streams. The relative infancy of tidal stream technology mirrors the situation of the early stages of the wind industry. Currently there is a wide range of devices under various stages of development with no clear sign of which will be the most successful (SDC, 2007). Irrespective of design, demonstration prototypes and their subsequent commercial successors must be capable of being installed, operated, maintained and decommissioned in an environmentally sustainable manner within an aggressive marine environment.

This paper provides an overview of the multidisciplinary activities of the tidal stream programme within the Welsh Low Carbon Research Institute, which set out to identify the research procedures required in order to assess the suitability of tidal stream turbine deployment sites in Wales. A candidate site was chosen and subjected to extensive hydro-environmental, hydrographic and hydrodynamic surveys over a 12-month period. Field data were then used in subsequent computer simulation studies to model the environmental effects of deploying tidal stream turbines in the ocean. This paper provides an overview of the research carried out during the project and the details of each discipline will be provided in individual papers by the respective subject authors.

\section{THE CANDIDATE SITE}

A site was selected on the basis of being typical of the type of area capable of tidal stream turbine deployment. The $1 \mathrm{~km}^{2}$ site is in the Bristol Channel, off the south Wales coast centred at position $51^{\circ} 20 \cdot 8^{\prime} \mathrm{N}, 3^{\circ} 29 \cdot 6^{\prime} \mathrm{W}$, approximately 3 nautical miles south of Llantwit Major (Figure 1).

A totally submerged horizontal axis tidal stream turbine with a swept blade diameter of $10 \mathrm{~m}$ (Figure 2) was chosen as a typical case on which to base the subsequent hydro-environmental research within this programme of work. Figure 2 includes sea surface levels at highest and lowest astronomical tides (HAT and LAT respectively), and the effect of storm surges and waves on sea level.

The Bristol Channel was identified as a potential location for marine renewable technologies having sufficient tidal flow, depth, access to ports and grid connectivity for device deployment. The Bristol Channel has tidal currents exceeding 


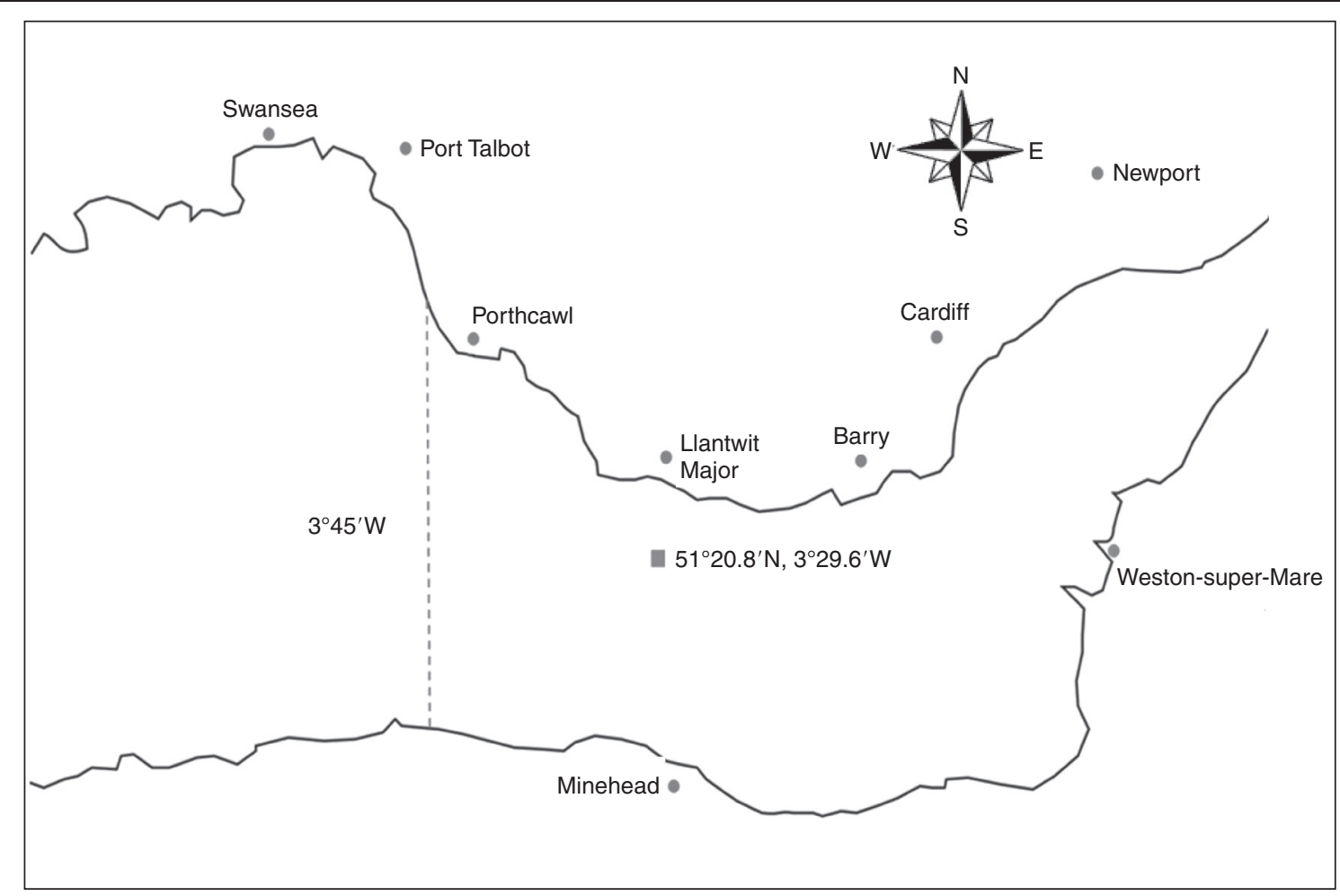

Figure I. Position of candidate site in the Bristol Channel

Storm surge level $+17.50 \mathrm{~m}$ Max. wave peak $+15.90 \mathrm{~m}$

HAT $+13.50 m$

HW-4 h pilot boarding $+2 \cdot 0 \mathrm{~m}$ LAT $0.0 \mathrm{~m}$ (chart datum) Min. wave trough $-2.4 \mathrm{~m}$

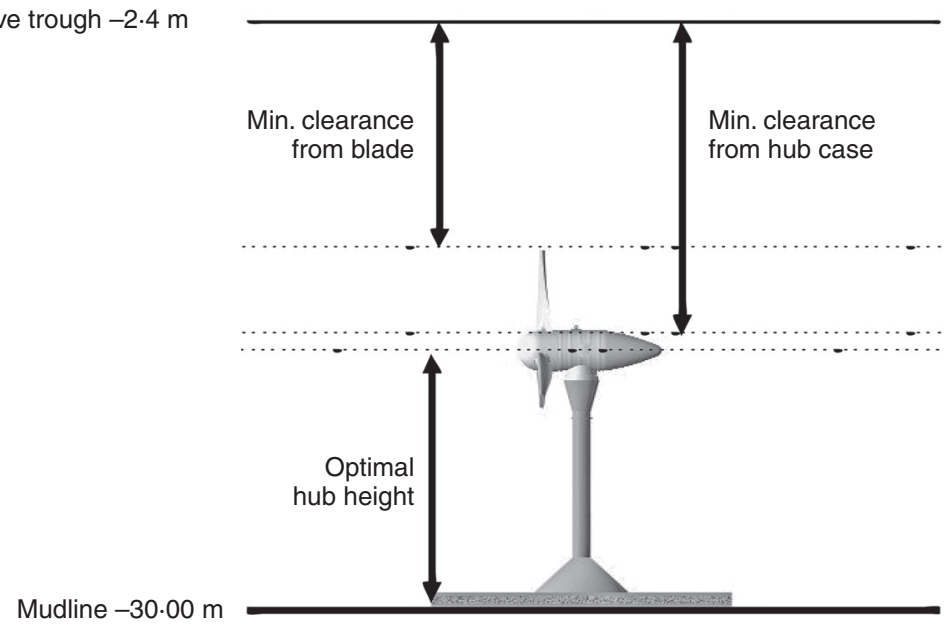


$2.3 \mathrm{~m} / \mathrm{s}$ ( $4.5 \mathrm{knots})$ at spring tide with the currents predominantly rectilinear to the coastline (Uncles, 1984). The currents are asymmetric due to channel topography, resulting in a stronger but shorter flood than ebb (Huntley, 1980). The Bristol Channel/Severn estuary also has one of the largest tidal ranges in the world (up to $13.5 \mathrm{~m}$ ) and as such is currently the topic of a Department for Business Enterprise and Regulatory Reform (BERR) feasibility study into extracting energy from tidal range devices. The Bristol Channel is also known to be a very energetic system that provides the power for sediment mixing and transportation (Glover, 1984). The bottom topography is complex and generally shallower than $50 \mathrm{~m}$, but at some points toward the east of the channel the depth is less than $10 \mathrm{~m}$ as the channel narrows becoming an estuary. In contrast, the western part of the channel reaches depths of $100 \mathrm{~m}$ in the Celtic Deep.

\section{INTERACTION WITH SEA USERS}

The Bristol Channel is used by the maritime community for various activities such as dredging, fishing, commercial traffic, recreation, archaeology, sewage disposal and cabling for both power and telecommunications. Some of these may potentially conflict with the deployment of a device at the site (MCA, 2004).

The Bristol Channel is used as a prominent shipping route as there are a number of large ports located throughout the Bristol Channel and Severn estuary region. Personal communication with the navigation safety branch of the Maritime and Coastguard Agency (MCA, 2007) revealed that the inner Bristol Channel has a number of large vessels passing through it on a daily basis. The MCA data indicated that in an 8-day period in mid-August 2006, a total of 87 ships of over 300 gross tonnage were detected through the waters offshore of the Vale of Glamorgan. Of the 87 vessels detected, 57 were dry cargo and 14 were tankers; the remainder were passenger vessels, dredgers and tugs. Table 1 shows the range of sizes, drafts and speeds of vessels operating in the inner Bristol Channel throughout this period. The greatest number of vessels of over 300 gross tonnage passing through the region on a single day was 19 (15 August) and the minimum was 2 (12 August). The area is clearly a well used and busy stretch of water.

Consideration of the destination ports of the vessels observed during this period shows that the Bristol Port Company (BPC) had the largest number of vessels operating; this would be expected due to the size and scale of the Bristol operations. Most vessels were travelling to ports that are the furthest east within the Bristol Channel/Severn estuary and any activity that could potentially reduce their economic viability would come against considerable opposition from such stakeholders.

\begin{tabular}{|lrr|}
\hline & Range & Mean \\
\hline & $30-245$ & $111 \cdot 6$ \\
Length: $m$ & $2-14 \cdot 2$ & $5 \cdot 6$ \\
Draft: $m$ & $1 \cdot 5-22 \cdot 1$ & $15 \cdot 3$ \\
Speed: knots & & \\
& & \\
Table I. Size of vessels travelling through the inner Bristol \\
Channel on 8-15 August 2006 (MCA, 2007)
\end{tabular}

Further correspondence with active pilots during 2007 indicated that vessels are a maximum of $140000 \mathrm{t}$ displacement but vessels of $80000-90000 \mathrm{t}$ displacement are the most common as they have the best economies of scale. However, the cost of running vessels can vary from year to year and thus the size of vessels can vary over time. This must therefore be considered when deciding on a suitable position for a tidal stream site. Most large-vessel traffic passes to the south of the site on the way towards the Bristol Channel pilot boarding area to the east of the site. This designated area is used to take on board pilots to bring large vessels into the eastern ports of the Bristol Channel and as a result has a large amount of traffic movement.

Avonmouth and Portbury Docks are the most influential in the region, accommodating a range of vessels up to $130000 \mathrm{t}$ displacement and draught up to $14.5 \mathrm{~m}$. However, BPC has proposed plans to expand Avonmouth Docks to include a deep water berth for container ships. The berths will accommodate vessels with a draft of up to $16 \mathrm{~m}$, meaning that the Bristol Channel/Severn estuary would require some dredging of the seaward approach along the shipping lane. It is reasonable to assume that the larger container ships would follow a lane towards the south of the candidate site.

As water depths exceed $20 \mathrm{~m}$, the site itself can also be used as a shipping lane. Shipping traffic at this location is less than that identified passing to the south, although there are a number of vessels over 300 gross tonnage using the site as a route through the Bristol Channel. The vessels using the area consist of dredgers, passenger vessels and dry cargo (MCA, 2007).

\section{I. Aids to navigation}

Vessels that pass the site are not piloted and the shipping lane in this area is not as well defined as that in the east, which could cause some concern to members of the shipping sector (i.e. pilots and Chamber of Shipping). Sufficient use of aids to navigation should minimise navigational risk (IALA, 2008); however, with the high tidal stream during spring tides, there is a risk of buoys being displaced. Further investigation into the feasibility of placing buoys in this area will be required.

Discussions with an active pilot highlighted the concerns of most pilots - the risk of collision between vessels and the turbine due to strong tides in the area. However, the presence of other features (e.g. sewage pipelines that extend out into the channel) requires the installation of aids to navigation in order to minimise the risk of collision with vessels. The risk of collision with a tidal stream device will therefore need to be minimised by the use of sufficient aids to navigation and a minimum under-keel clearance between the rotor and the sea surface at all times, including LAT. After feedback from maritime stakeholders on the positioning of a pre-commercial tidal stream device within the Bristol Channel, a clearance depth of $11 \mathrm{~m}$ has been suggested by the Chamber of Shipping for a single turbine at this particular site.

IALA recommendation 139 indicates that for tidal stream technology and navigation to coexist safely, any device must be marked by a yellow buoy with a yellow flashing light (IALA, 2008). The sequence of the flashing will always be different to the flashing sequences of buoys fitted with white lights. The 
light from this aid to navigation will have a range of 5 nautical miles (approximately $9.5 \mathrm{~km}$ ). The positioning of a device $3 \mathrm{~km}$ offshore could result in the aid to navigation being visible from the shoreline. However, as the region is mostly rocky cliff shoreline, residential areas in the vicinity should not be affected by the light.

\subsection{Other aspects}

3.2.1. Fishing. The waters of the inner Bristol Channel are not regarded for fish resources and as a result the site is not used for economic fishing. The Office of National Statistics has no evidence of anyone in the Vale of Glamorgan employed in the commercial fishing industry (ONS, 2001).

3.2.2. Dredging. The Bristol Channel has a number of sites used for dredging, including one south of Porthcawl that is approximately $12 \mathrm{~km}$ from the site. There is thus frequent dredging traffic near the site of interest (WAG, 2004).

\subsubsection{Recreational and other sea users. With respect to} recreational sea users, most of these vessels are under 300 gross tonnage and thus have not been recorded by the MCA navigation safety branch and have not been discussed in the previous section. Recreational sea users include fishing boats, yachts and any vessel associated with water sports. Such activities are not frequently observed in the localities of the site because of the high volume of large-vessel traffic in the area, the fast tidal stream and the relative absence of fishing opportunities.

\subsubsection{The seabed. There are no known seabed power or} telecommunication systems in close proximity to or within the $1 \mathrm{~km}^{2}$ site. There are also no dredging areas, dumping grounds or wind farms and their cables. Discussions with the Crown Estate and use of their GIS database confirmed that the site does not conflict with any other seabed users. However, the wrecks of William Margaret and Sir Francis Drake are less than $1 \mathrm{~km}$ north-west of the site. These are historic wrecks under the care of the Royal Commission on the Ancient and Historical Monuments of Wales and thus their conservation and preservation must be maintained.

\section{ENVIRONMENTAL SCOPING}

There is a long history of construction in the marine environment and protocols for environmental impact assessment (EIA) and compliance with regulations are well developed. It is generally accepted that developments that contain any novel elements should undergo a greater degree of investigation.

The deployment of tidal stream devices is novel in two respects. Firstly and most obviously, the devices themselves are new designs with most containing a large slowly spinning turbine rotor. Secondly, tidal stream devices will be deployed in highcurrent conditions that are usually avoided by other forms of marine construction. Fast currents generally remove all soft substrate from the seabed and hard rocky seabeds present additional sampling problems, especially with gear towed at or close to the bottom. New technologies also give rise to new perceptions and environmental concerns from the general public; tackling these concerns early on in the process will help with public support for the technology.
Surveying challenges of fast currents and hard substrates are increased in the Bristol Channel by very high sediment loads in the water, resulting in very low underwater visibility. Fish in the Bristol Channel are of commercial and recreational importance. A number of fish species of conservation importance migrate through the area, including twait shad, allis shad, river lamprey and atlantic salmon - all of which are referred to in the IUCN regional red data list (IUCN, 2010) and the UK biodiversity action plan (BAP) (BSG, 1995).

\section{I. Scope of the survey work}

The survey work undertaken in the project covers the second stage of site selection for tidal energy. Several first-stage studies have been undertaken in the past, often using geographical information system (GIS) databases containing outputs from regional tidal flow models. Typically this work uses a grid spacing of the order of hundreds of metres and is very good for determining regions of interest. The most recent comprehensive work in Welsh territorial waters was undertaken in 2006 (PMSS, 2006). Outputs from the PMSS work were used with a desk study of existing literature to define a $1000 \mathrm{~m} \times 1000 \mathrm{~m}$ square within which a demonstration turbine or small array could be positioned. In this desk study, the team completed the macro-siting stage of the process. The objectives of the second-stage survey were to

(a) gather enough information regarding bathymetry, flow patterns and turbulence to have confidence in the input parameters of the computer models

(b) establish (or otherwise) the presence of protected species in the area

(c) benchmark levels of salinity, suspended sediment, temperature and the presence of plankton prior to device installation.

The desk study established that two surveys were unnecessary at the site: a geophysical survey (isopachyte) was not needed due to the scoured bedrock seabed and marine mammal surveys were not useful as there are no sightings this far east in the channel. The high sediment levels and poor visibility mean that marine mammal activity stops around $15 \mathrm{~km}$ further downstream (west) of the site (ABPMER, 2005).

Following on from this, and once a microsite has been identified, a number of further third-stage surveys could be undertaken

(a) detailed video surveying of the proposed installation area

(b) collection of further samples from the site by dive survey, remotely operated vehicle (ROV) or grab

(c) long-term bottom-mounted acoustic Doppler current profiler (ADCP) to establish tidal harmonics

(d) geotechnical core drilling (which might cost as much as the entire programme thus far)

(e) wave climate monitoring, possibly with surface-mounted buoys.

\subsection{Seabed survey}

Field data were collected at the candidate site for 12 months from June 2007 using the Swansea University vessel $R V$ Noctiluca. Broad-scale bathymetry was measured using a single-beam Simrad ES-60 echosounder, processed using Olex software. Bathymetric data were collected by the Olex system in 


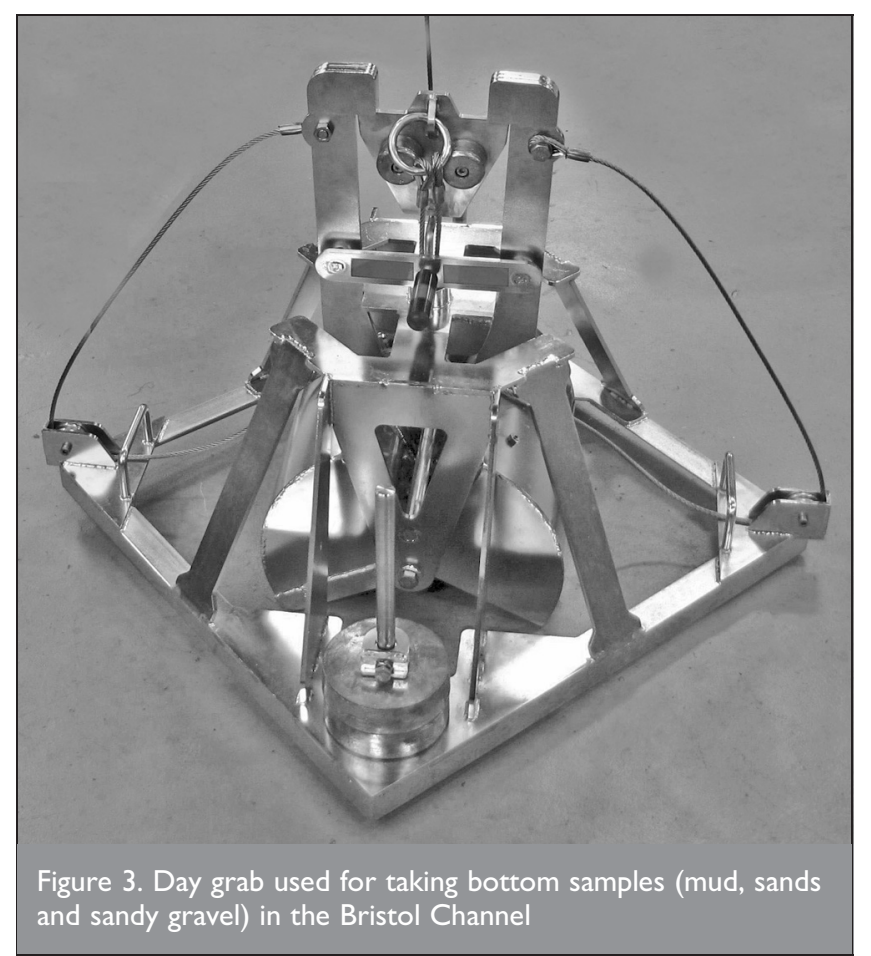

real time during transects for echosounder detection of fish. Bed samples were taken by lowering a day grab (Figure 3) to the seabed; this automatically released the grab jaws and took a sample of up to 15 litres of sediment.

A colour video of the seabed was taken using a Submertec Seaspy system. It was found that usable pictures were obtained when the bottom water turbidity was less than 50 ntu measured with a YSI 600 series sonde.

Grab sampling failed when the jaws of the grab were jammed by large pebbles. A small number of samples from the deeper channel at the west side of the site contained gravel. Video samples were only possible either side of slack water on low water neap tides. They confirmed that the seabed at the site consisted of bedrock, cobbles and pebbles with some small patches of gravel.

\subsection{Water column survey} It is very difficult to bottom trawl on a rough hard seabed. In an area of strong tidal flows and a high tide range, snagging a net is very dangerous. Trawls also only give the presence of caught species at the site (within the track and mouth opening of the net), not the positions of individuals horizontally and vertically.

Echosounders can detect fish and other species in the water column and give their exact location. To detect water column targets, a Simrad ES-60 was used with a dual-frequency singlebeam transducer. Transects were carried out within the area shown in Figure 4 in a north-south direction (i.e. normal to the tidal flow) at intervals of $50 \mathrm{~m}$ and a speed of 1-2 m/s.

Echosounder data were analysed using SonarData Echoview software. Target numbers are plotted against depth below the sea surface in Figure 5.

Most large single targets (fish) were found to be close to the seabed up to a height of $5 \mathrm{~m}$ from the bottom. Large numbers of small targets were found in the surface $5 \mathrm{~m}$ and were thought to be plankton and debris (cast seaweed and rubbish and plant material from riverine inputs). This, coupled with saturation effects at the tip of the sonar cone, accounts for the saturation levels (target levels above 50) observed in the top $13 \mathrm{~m}$ of the water column. When the positions of the targets were plotted and compared with the bathymetry, it was found that large numbers of fish were detected along the edges of the small channel running east-west through the site. The distributions of fish relative to the seabed show that fish abundance is low in the depth range that would be occupied by a tidal stream turbine (5-20 $\mathrm{m}$ above the seabed).

\subsection{Hydrographic and hydro-environmental measurements}

Field data were measured from the Cardiff University research vessel $R V$ Guiding Light using a boat-mounted single echo sounder fitted with CurrentSurveyor and WinADCP software and a Multibeam SWATHE system. The survey was undertaken during spring tides and a total of 14 transects were run within the $1 \mathrm{~km}^{2}$ candidate site along the same line perpendicular to the ebb tide in an alternating northerly to southerly direction. Details of the survey are given elsewhere (O'Doherty et al., 2010). Current flow profiles were also taken throughout a tidal cycle while the vessel was moored. ADCP profiles were used to study power attenuation effects on turbine performance. The bathymetry of the $1 \mathrm{~km}^{2}$ site is shown in Figure 6 . Measured 


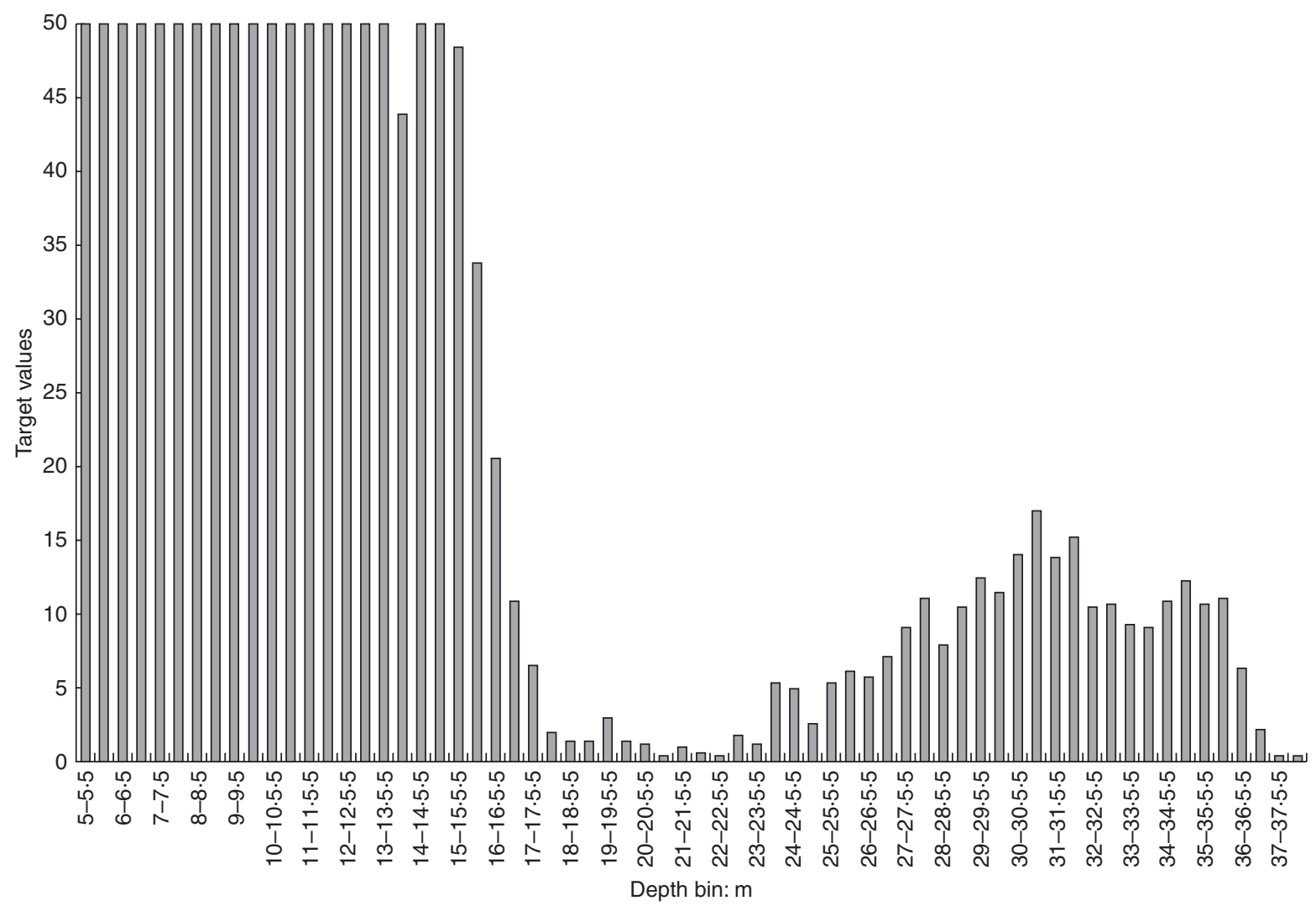

Figure 5. Abundance of targets throughout the water column at the candidate site

bathymetric and hydrodynamic data were used in subsequent computer simulations.

\section{COMPUTATIONAL FLUID DYNAMICS MODELLING OF A TYPICAL TIDAL STREAM TURBINE}

The basis of this computational model of the impact of a water turbine is the ability to describe the likely influence of the device on fluid flow. Section 6 describes a more detailed blade model used for device design. While a description of the fine detail of the transient nature of the flow caused by the motion of the blades is feasible, it is still computationally expensive. A time-averaged boundary element based algorithm was thus used to resolve the influence of the blades. Sources are added into the momentum equations based on the geometry, lift and drag of the blades (Orme, 2007). The method uses a co-located finite volume method using unstructured meshes (Croft, 1998). The pressure-velocity coupling is resolved through a variant of the Simple algorithm (Van Doormaal and Raithby, 1984) and pressure oscillations are suppressed through the use of RhieChow interpolation (Rhie and Chow, 1983), together with the standard $k-\varepsilon$ turbulence model (Launder and Spalding, 1974).

One of the questions raised about tidal turbines is their interaction with marine life, in particular their effect on cetaceans, seals and protected fish species. The nature of the interaction is related to the psychology of marine life: for example, does the turbine attract the attention of marine life or do they stay away from it? The proximity of particular marine species to a tidal stream turbine will be site dependent. Throughout the surveying period, visual surveys were taken in and around the candidate site and 


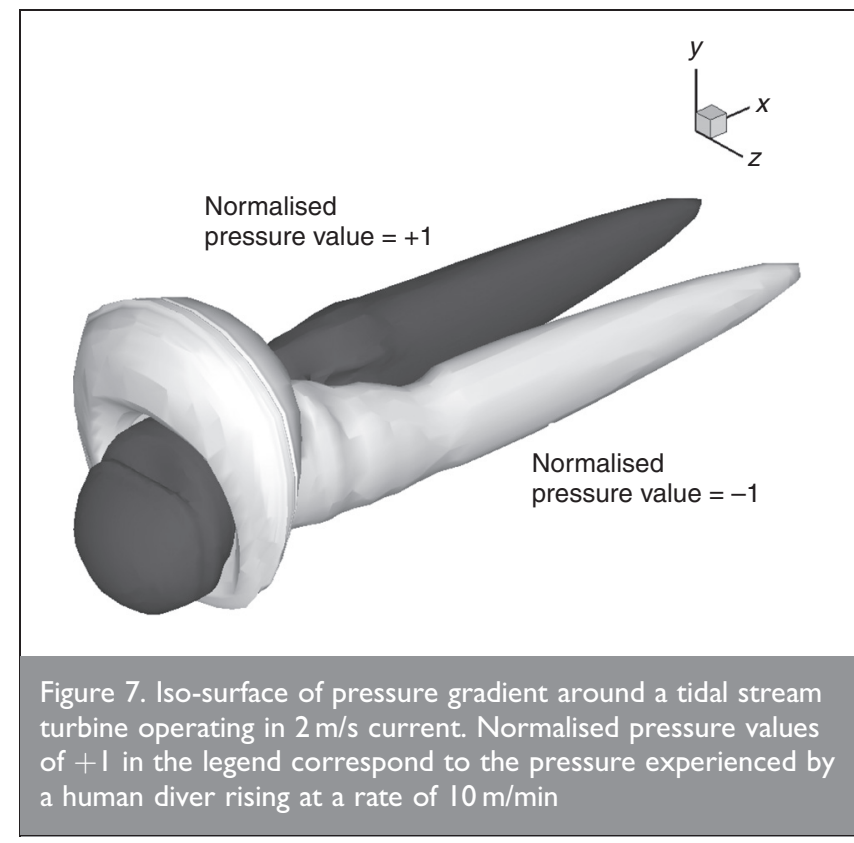

no marine mammal observations were noted. This particular site in the Bristol Channel was not thought to be frequented by cetaceans or other marine mammals (ABPMER, 2005). Computer models therefore concentrated on the effect of rotating turbines on fish.

Numerical modelling can provide an indicative demonstration of the potential for damage to occur. This work examined two such questions. The first relates to determining the 'event horizons' for a given maximum swimming speed and escape strategy. Within the event horizon surface, a fish is certain to pass through the rotor. The second effect that was investigated is the areas where fish would pass through rapid variations in pressure.

It is known that fish suffer effects somewhat similar to decompression sickness if they are subjected to rapid changes in pressure. Figure 7 represents the pressure fields around a horizontal tidal stream turbine operating in a $2 \mathrm{~m} / \mathrm{s}$ flow. A channel width of $60 \mathrm{~m}$ was found to be an optimum balance of model accuracy and computing time. The measure presented in Figure 7 is a transient gradient of pressure calculated along a streamline. The value is normalised by the safe rise rate for a human diver $(10 \mathrm{~m} / \mathrm{min})$. The iso-surface is plotted at values of +1 and -1 . Although it cannot be seen in the figure, within centimetres of the blades pressures exist up to five times greater than those associated with $10 \mathrm{~m} / \mathrm{min}$ rise rates.

Calculation of the event horizons assumes that a fish can move at a prescribed maximum speed relative to the current. It was assumed that acceleration was infinite, so motion was always at this relative speed. An escape strategy was also associated with the fish, which in this study defines the direction it will travel relative to the free current. A fish was placed at the centre of each mesh element and tracked using a particle tracking algorithm until it passed through the plane of the turbine. The distance from the centre of the turbine as marine life passed through the plane determined whether the original position was inside or outside the event horizon. Figure 8 shows plots of the event horizon when the fish moves at right angles to the free current with a maximum speed of (a) 0.5 and

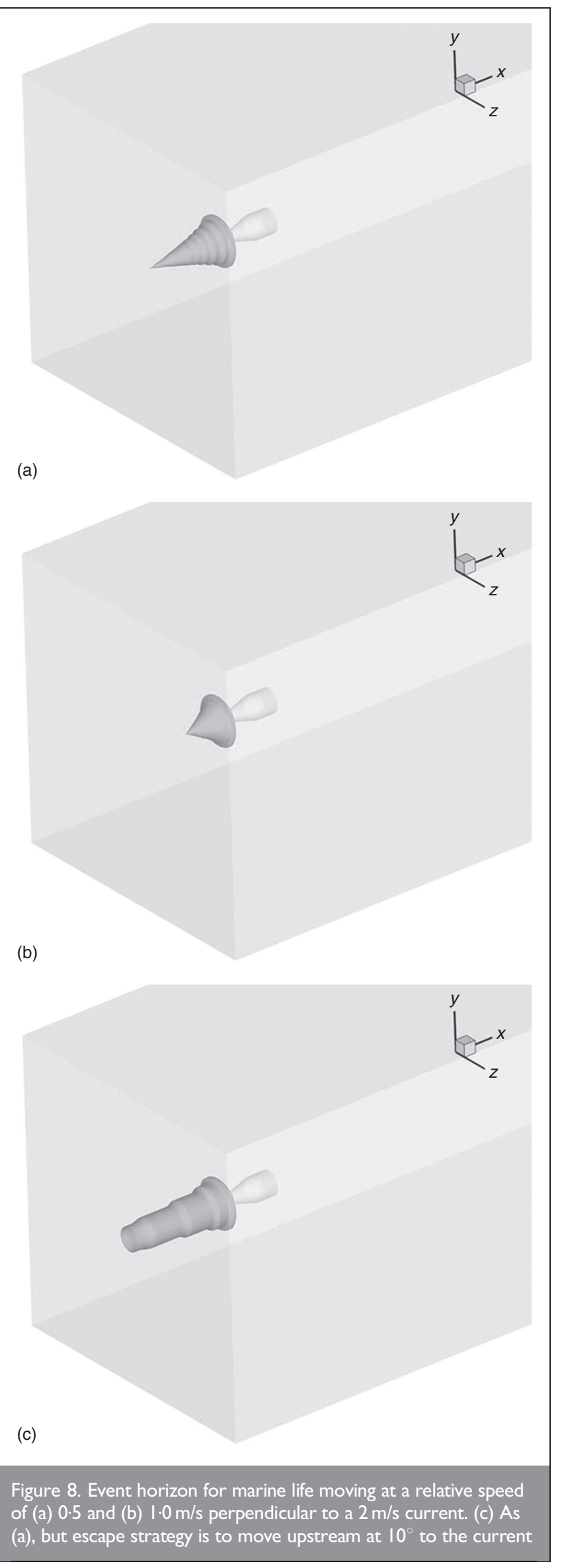

(b) $1.0 \mathrm{~m} / \mathrm{s}$. Figure 8 (c) shows the event horizon when the maximum speed is $0.5 \mathrm{~m} / \mathrm{s}$ but with the escape strategy is changed so that motion is in an upstream direction at $10^{\circ}$ to the current. 


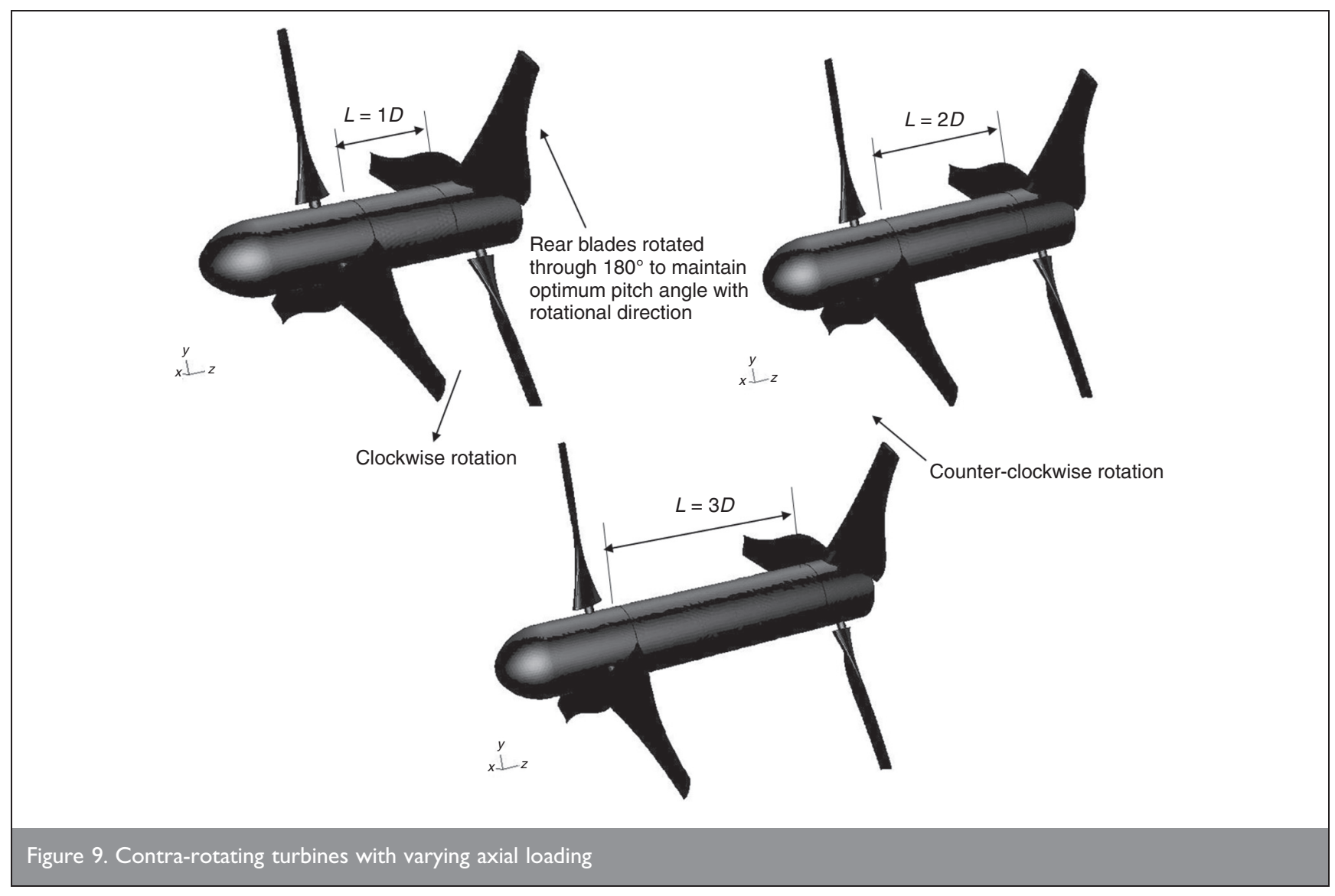

The pressure gradients associated with the modelled device and the very short exposure to the highest gradients would result in no significant damage to the majority of marine life. Bird strikes on wind turbines clearly indicate that purely being able to move quickly enough is not the only attribute required to avoid danger. Most marine life will also be able to move quicker than the current, but visibility in the marine environment is often poor. Whether a marine device can be seen, sensed or heard will be an important component in the risk of contacts. The psychology of marine life to the presence of the device will determine their response. Pressure changes do provide a potential risk to marine life. While the location of this risk may also be coincident with blade contacts, the risk should not be ignored especially for larger devices. Despite these concerns, the tools described in this section provide a useful insight into aspects of the potential risk of damage caused by marine turbines and a mechanism for comparing relative risks of different devices.

\section{MODELLING POWER EXTRACTION}

To study the potential power extraction, the turbine was optimised for power output using a quasi-static computational fluid dynamics (CFD) model. The model was then used to study operational parameters (power output, axial load and torque all as functions of angular velocity, etc.) under ideal conditions forming the reference conditions. The study was then extended to consider how the turbine's performance changes as parameters vary with actual data collected at the candidate site.

In summary, the CFD reference model demonstrated the ability to capture key performance characteristics of the turbine design.
Peak power and axial thrust calculated via CFD show good agreement with power estimates quoted in the literature providing a qualitative estimate on the performance for the current design and a first-order validation for the CFD model.

\section{I. Axially spaced twin turbines}

Two sets of turbines, mounted on inline shafts, were modelled. In the case of near-field spacing, defined here as the point at which the wake reaches a minimum velocity (typically up to four turbine diameters downstream of the turbine), double contra-rotating $10 \mathrm{~m}$ diameter turbines were modelled (Figure 9). For this work, the rear row of blades were positioned no more than three hub diameters downstream of the front row of blades since no additional gains in power extraction were achieved beyond this given the conditions of the study (O'Doherty et al., 2009). By performing angular velocity sweeps with the turbines separated at an axial distance of three hub diameters and a constant tidal velocity, the total power extracted from the front and rear turbines was determined (Figure 10).

It was noted that by positioning the turbines at one hub diameter apart rather than three hub diameters, the proportion of energy extracted from the rear turbine increased. However, this resulted in a corresponding loss in energy extracted from the front turbine, producing an approximate net balance in output between the two. The work also indicated that there may be some merit in closer spaced turbines for a small increase in the overall power output and reduced wake length, at least under near-field conditions (e.g. between 0.5 and 2 hub diameters for such a design). The advantage noted in wake length between the closely spaced configuration and the singleturbine design was that there was an $87 \%$ recovery of the free 


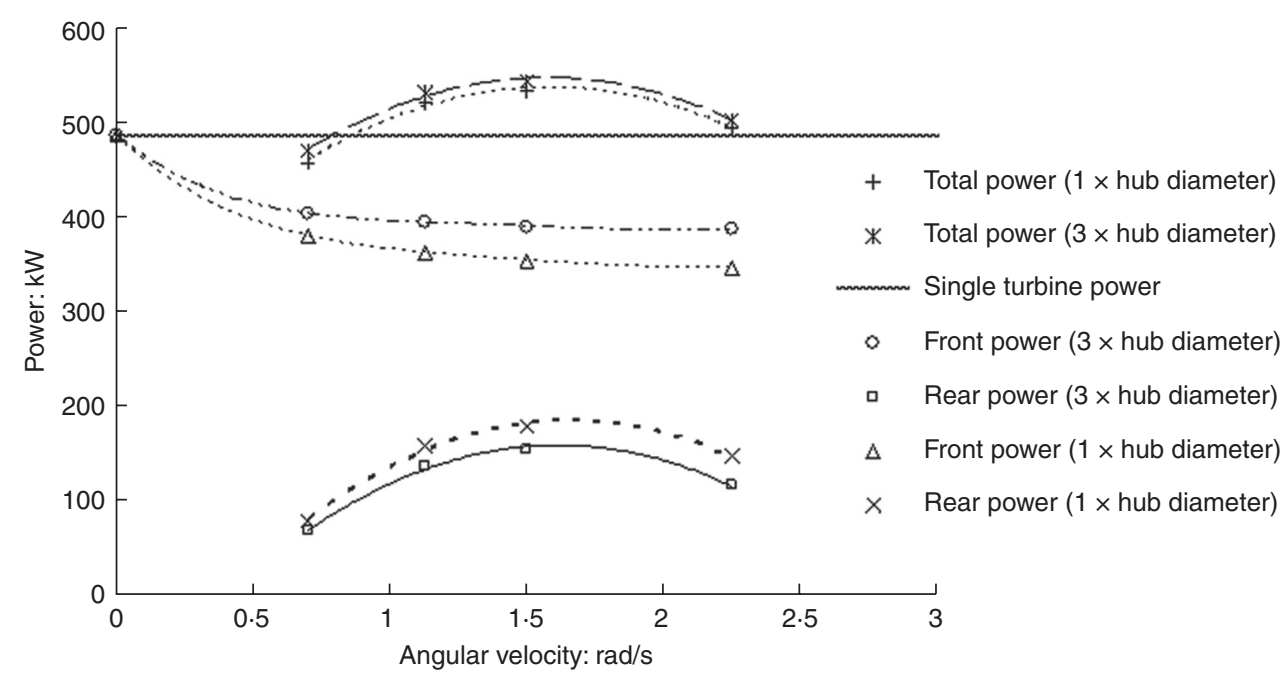

Figure 10. Power curves for $10 \mathrm{~m}$ diameter contra-rotating turbines

stream velocity at 10 turbine diameters downstream while for the single-turbine design a 52\% recovery was indicated at the same downstream location. However, the initial study on a near-field axially spaced design indicated that there was only a $5-10 \%$ increase above a single turbine, which is unlikely to be sufficient to cover any extra cost associated with more complex gearing and increased hydrodynamic loads. However, if the power is compared with a single turbine with a stanchion, for a diameter the same as the turbine hub, there is up to $30 \%$ increase in power extracted (O'Doherty et al., 2009).

\subsection{Turbine arrays}

For the array study, three conditions were modelled using CFD. Firstly, three $10 \mathrm{~m}$ diameter turbines were positioned in a single row, across a $140 \mathrm{~m}$ wide by $20 \mathrm{~m}$ deep channel, all rotating in the same direction. Blockage effects were studied by varying the lateral spacing between the turbines. For the three-turbine case, the turbines occupy $9 \%$ of the cross-sectional area of the channel of water modelled. For the two-row array, two configurations were studied: a fourth turbine was positioned five turbine diameters directly to the rear of the middle turbine and then between the centres of the two outer turbines. When viewed from an upstream position, the array of four turbines effectively occupied $12 \%$ of the channel's cross-sectional area.

Due to blockage effects and an increase in flow around the outside of the row, the two outer turbines experienced an increase in efficiency in all models, but the phenomenon was more pronounced in the counter-rotating cases. A further and more pronounced increase in efficiency was noted in the turbines when closely spaced across the channel. This was apparent at both extremes of the spacing range studied. The highest increase in efficiency of 4\% (Figure 11) was obtained with a row of closely spaced counter-rotating turbines.

Since the rotational directions of the turbines alternated across the row, they acted in a 'gear wheel' manner, so reducing the drag effects. For the turbines positioned in the second row, the results were somewhat intuitive and showed that considerable losses in performance occur by placing a turbine directly in the wake of an upstream turbine, as can be seen in Figure 12.
With a second-row turbine at five turbine diameters behind the centre turbine (turbine D in Figure 12), power extraction was reduced by $40 \%$. However, with a lateral spacing of two turbine diameters across the channel and the second-row turbine aligned between the two outer turbines (turbine E), the reduction in power extraction was limited to $14 \%$. These reductions were due to redistribution of the flow within the front row's wake and increased turbulence. This work formed a good foundation for further studies on energy extraction and blockage effects when using turbine arrays in narrow channels. This is particularly important with regard to providing an assessment of turbine placement/positioning within a 'farm' arrangement using non-dimensional characteristics (based on turbine diameters).

\section{HYDRO-ENVIRONMENTAL MODELLING}

Although every fixed tidal stream device has a small footprint, the overall impact can only be investigated by considering the scale of each installation (i.e. the number and size of devices installed) and the total number of installations around the coastline (SDC, 2007). In addition, the environmental impact of energy extraction is not necessarily restricted to the immediate area around the extraction site (Bryden and Couch, 2006).

The Divast (depth integrated velocities and solute transport) and Faster (flow and solute transport in estuaries and rivers) models were modified and set up to investigate far-field impacts of arrays of stream turbines in the Bristol Channel and the Severn estuary. This far-field impact modelling has enabled the teams to investigate any potential conflicts of use of different marine renewable energy devices (e.g. the proposed Severn barrage and tidal stream turbines). The western boundary of the model is clearly seen in Figure 13, while the eastern extremity is at the tidal limit (Harris et al., 2004).

Divast and Faster are based on finite-difference implicit solutions of the Navier-Stokes and solute transport equations in two and one dimensions, and for the hydrodynamic and sediment transport/water quality process predictions respectively (Kashefipour et al., 2002). The hydrodynamic sub-model 


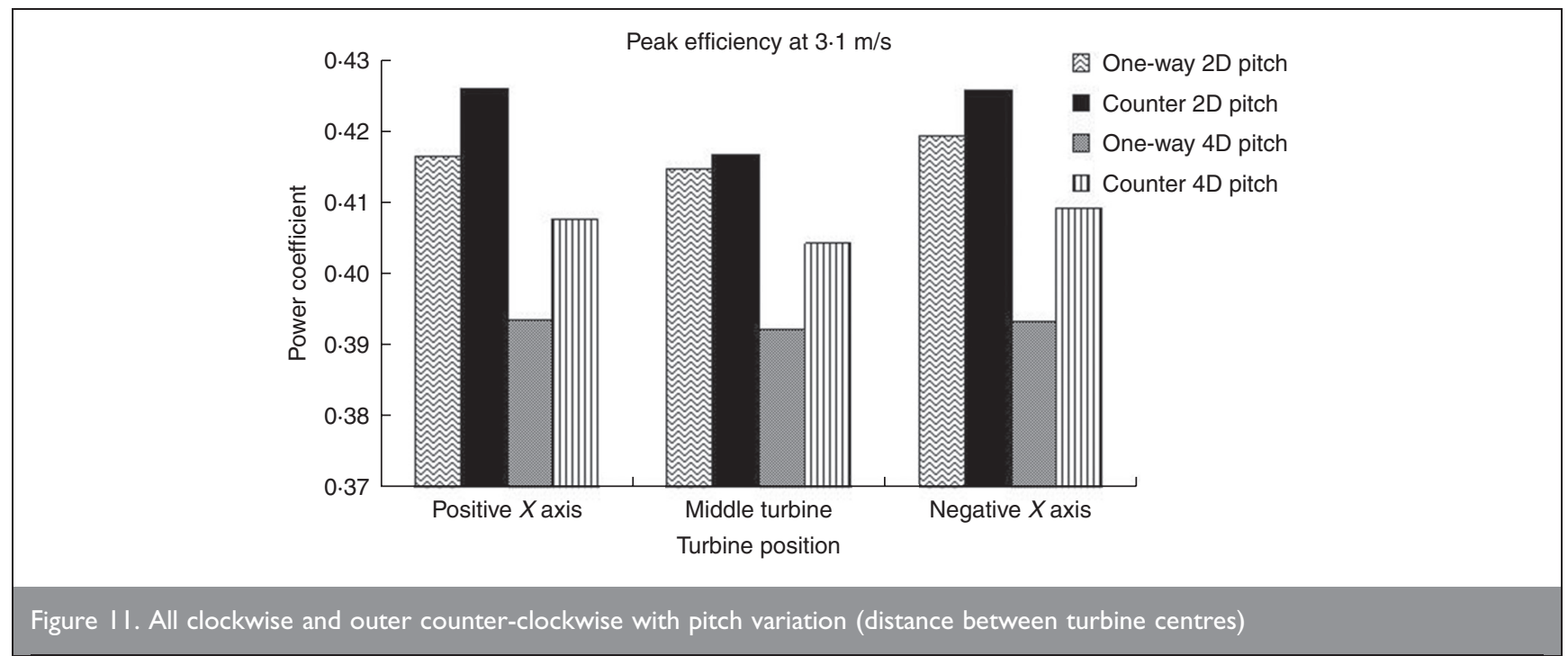

includes the effects of bed friction, the earth's rotation, turbulence and wind action. The solute/sediment transport sub-model includes the effects of dispersion, diffusion, decay, erosion and deposition, and adsorption and desorption. The models are capable of simulating water elevations, tidal currents, cohesive and non-cohesive sediment fluxes and various water quality parameters (e.g. salinity, faecal indicator organisms, nitrates, phosfates and dissolved oxygen) in river, estuary and coastal environments and as functions of time. The models also include water quality processes such as sedimentbacteria interaction (Yang et al., 2008) and dynamic faecal bacteria decay rate (Stapleton et al., 2007) as well as health risk assessment for bathing water compliance and flood hazard risk assessment.

To include stream turbines in the model, using the extraction coefficient factor produced by a CFD model, the amount of energy extracted by each turbine was calculated at each time step and used in the model as a momentum sink. Introducing the turbines as a momentum sink enabled dynamic coupling of the hydrodynamic, sediment transport and water quality processes to be included in the same model. For example, Figure 13 demonstrates the predicted suspended sediment level in the Bristol Channel and the Severn estuary including an

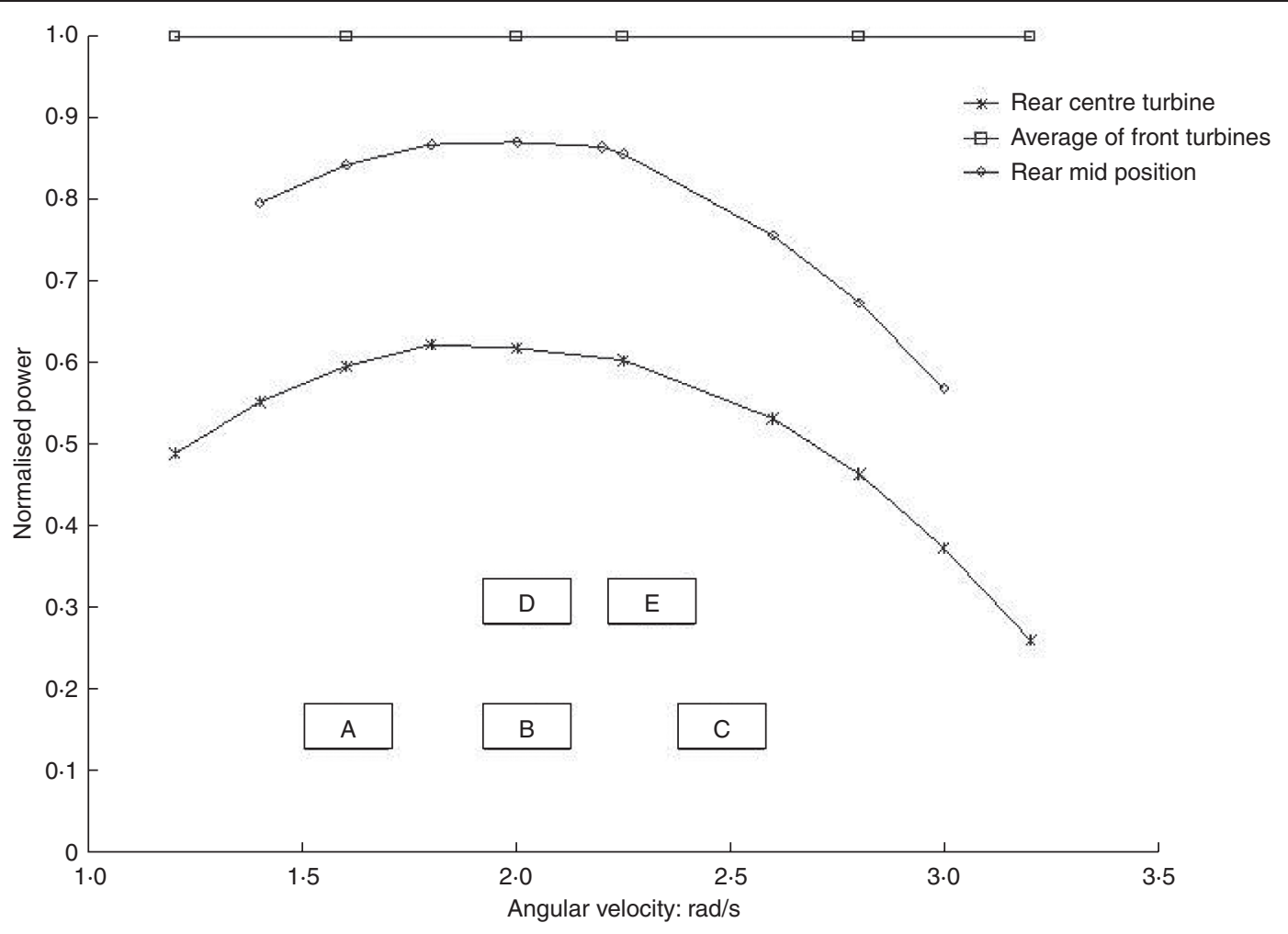

Figure 12. Normalised power curve for rear turbine D behind turbine B and turbine E behind mid-point of turbines B and C 


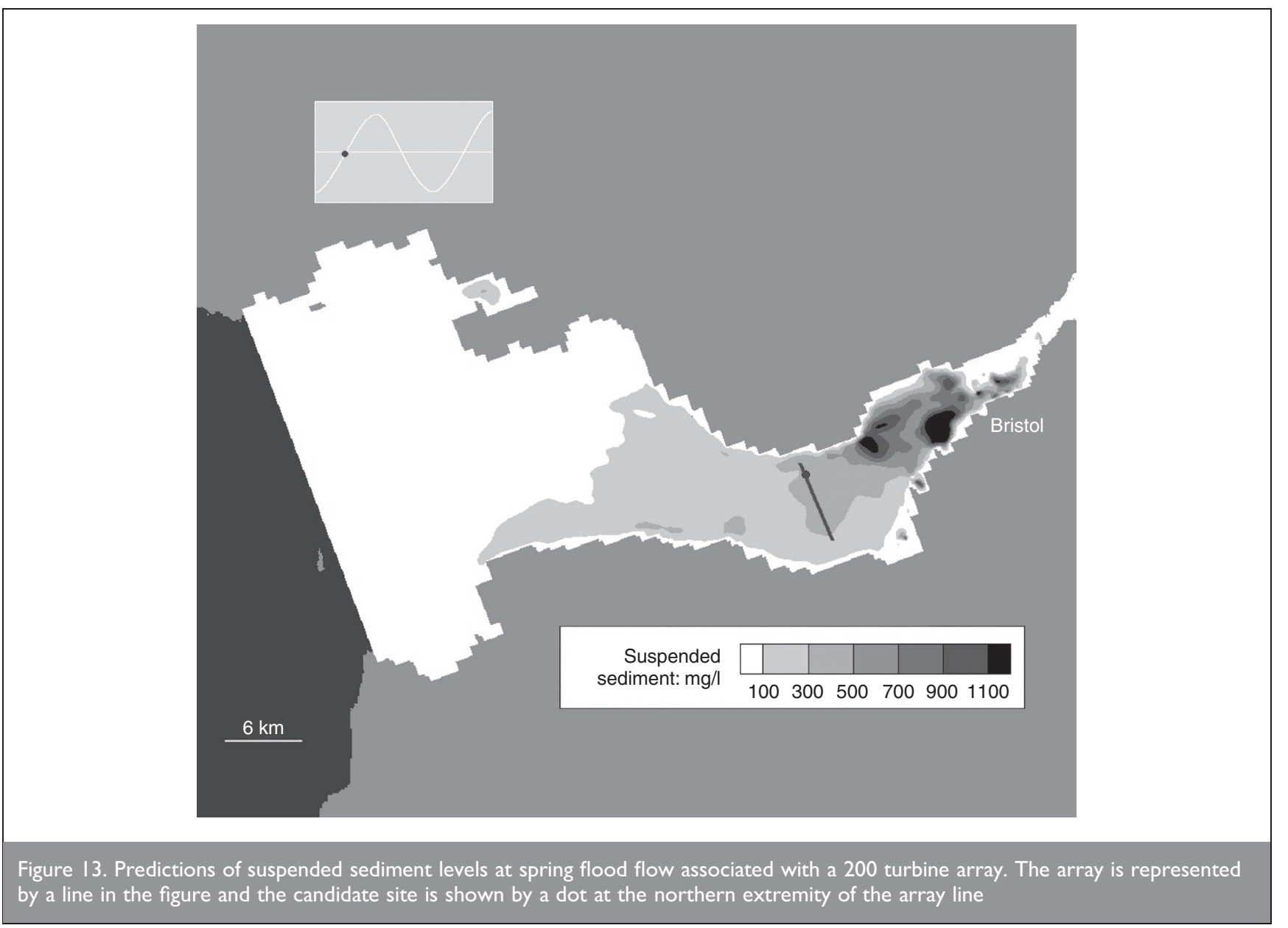

array of 200 turbines distributed along the line indicated in the figure. The candidate site is represented by the dot at the northern end of this line.

\section{DISCUSSION}

A $1 \mathrm{~km}^{2}$ site in the Bristol Channel was chosen to be representative of a typical tidal stream turbine deployment area. This site has been subject to extensive hydrographic, hydroenvironmental and hydrodynamic field work aboard the research vessels of Swansea and Cardiff Universities. The field work has been used to develop appropriate numerical models of the site.

The work discussed in this paper has been an effective mixing of disciplines in a new area and has extended the knowledge at the interface. One of the aims of the project was to clearly understand the type of work required to characterise a site and this has been reasonably well achieved. This area has been extensively studied and recorded in the past and therefore the desk studies provided quite a high level of detail before any overhead of work at sea was undertaken. The first conclusion of this work is therefore that desk studies should be extensive before any offshore survey is undertaken. The desk work concluded that

(a) there would be a high sediment load and therefore lower levels of marine life

(b) the bottom would be scoured, and therefore settlement and scour of sediment in the presence of a turbine would be negligible (c) there are no marine mammals in the vicinity (probably due to the sediment load).

With the results of the desk study, a survey programme was devised using the two vessels for different purposes. The complexities of the site, the busy traffic and sailing time from the home ports all worked together to lead to the conclusion that experiments would only include surveys that could be conducted from the deck and that no instruments were left at the site for a long period of time. This is an important conclusion: many assume that the positioning of fixed longterm instruments is the first stage of data capture for a site, but this work has shown that significant information can be obtained from shorter-term surveys. The following conclusions were drawn from the vessel surveys.

(a) The site chosen was a well-mixed water column with suspended sediment. This implies that the impact of the mixing effects associated with whirl downstream of a tidal turbine will be negligible; however, protective coatings on the unit will need to be selected to avoid wear caused by sediment load.

(b) Sediment scour and/or deposition around the pile or associated with the turbine blade was not considered an issue at the site considered. Seabed maps show minimal sediment on the bedrock and this was confirmed by the surveys. Therefore, scour is not possible and any potential deposition in the wake of the turbine will be removed by continuing reversal of the flow.

(c) Fish detection studies showed that what fish were present were predominantly in areas away from the turbine, close 
to the sides of the channel. Any structure in the water has the potential for reef effects, and this is an area for further research.

(d) It was also found that the far-field impacts were of particular importance and should be investigated in detail as with the near-field impacts. The reduction in predicted tidal currents after including a proposed Cardiff-Weston barrage would affect suitable sites for tidal stream turbines and these sites may no longer be economically viable for tidal stream turbines if a barrage is built.

The CFD studies operate at every level of detail and therefore complement each other extremely well. At the most detailed level, the power extraction models explicitly model the blade surfaces and provide a good analysis of the blades themselves. These are, however, the most computationally demanding and the parametric work outlined here has required substantial resources. Treating the blades as a time-averaged momentum and energy change in the system significantly reduces computational load at the expense of blade level detail. The reduced computational time means that this model will be easier to use for array models and the wakes and interactions downstream of devices. Ongoing work is actively looking at the differences between the two approaches to determine if any significant flow features are removed by the time averaging. Finally, the largest scale models provide information on the whole channel and the interaction of the device (or array) with regional flows and associated parameters such as suspended sediment levels.

All of the research outlined in this paper has enabled the team to choose precisely (within $50 \mathrm{~m}$ ) a point at which a single demonstration turbine could be deployed. The point does not have potentially high-risk environmental or navigational impacts and has bed conditions suitable for installation. Further survey work can now concentrate on a much smaller area and it is now appropriate for long-term surveys to commence.

In conclusion, evaluation of a potential test site can only be achieved properly with the involvement of marine engineers, marine biologists, environmental scientists and key stakeholders appropriate to the site. Without this expertise and access to the data that each can bring to the project, key issues could be missed, causing delays to device deployment.

\section{ACKNOWLEDGEMENTS}

This work was undertaken as part of the Low Carbon Research Institute Marine Consortium (www.lcri.org.uk). The authors are grateful for the guidance, support and resources of the Marine Energy Task Group for Wales (www.metgwales.org). The authors wish to acknowledge the financial support of the Welsh Assembly government, the Higher Education Funding Council for Wales, the Welsh European Funding Office and the European Regional Development Fund Convergence Programme.

\section{REFERENCES}

ABPMER (ABP Marine Environmental Research Limited) (2005) Potential Nature Conservation and Landscape Impacts of Marine Renewable Energy Development in Welsh Territorial Waters. Countryside Council for Wales, Bangor, Research report No. 04/8.
Bryden IG and Couch SH (2006) ME1 - Marine energy extraction: tidal resources analysis. Journal of Renewable Energy 31(2): 133-139.

BSG (UK Biodiversity Steering Group) (1995) Biodiversity: The UK Steering Group Report - Volume II: Action Plans (Annex F - lists of key species, key habitats and broad habitats). HMSO, London. See http://www.ukbap.org.uk/ Library.aspx for further details (accessed 08/07/2010).

Croft TN (1998) Unstructured Mesh-Finite Volume Algorithms. $\mathrm{PhD}$ thesis, University of Greenwich.

Glover RS (1984) The Bristol Channel - a case for special treatment. Marine Pollution Bulletin 15(2): 37-40.

Harris EL, Falconer RA and Lin B (2004) Modelling hydroenvironmental and health risk parameters along the South Wales coast. Journal of Environmental Management 73(1): 61-70.

Huntley DA (1980) Tides in the Northwest European continental shelf. In The Northwest European Shelf Seas (Banner FT et al. (eds)). Elsevier, Amsterdam, pp. 301-351.

IALA (International Association of Marine Aids to Navigation and Lighthouse Authorities) (2008) Recommendation 0-139: The Marking of Man-made Offshore Structures. IALA, St Germain-en-laye, France.

IUCN (International Union for Conservation of Nature) (2010) Red List of Threatened Species, Version 2010.2. http:// www.iucnredlist.org (accessed 08/07/2010).

Kashefipour SM, Lin B, Harris EL and Falconer RA (2002) Hydro-environmental modeling for bathing water. Water Research 36(7): 1854-1868.

Launder BE and Spalding DB (1974) The numerical computation of turbulent flows. Computational Methods and Applied Mechanical Engineering 3(2): 269-289.

MCA (Marine and Coastguard Agency) (2004) MGN 275 (M): Proposed UK offshore renewable energy installations (OREI) - guidance on navigational safety issues. See http:// www.mcga.gov.uk/c4mca/mgn_orei_v2-2.pdf for further details (accessed 25/08/2007).

MCA (2007) Navigation Safety Branch. Personal communication.

O’Doherty DM, Mason-Jones A, O'Doherty T and Byrne CB (2009) Considerations of improved tidal stream turbine performance using double rows of contra-rotating blades. Proceedings of the 8th European Wave and Tidal Energy Conference, Uppsala. Uppsala University, Sweden, CD-ROM.

O’Doherty T, Mason-Jones A, O'Doherty DM et al. (2010) Considerations of a horizontal axis tidal turbine. Proceedings of the Institution of Civil Engineers, Energy 163(3): 119-130, doi: 10.1680/ener.2010.163.3.119.

ONS (Office of National Statistics) (2001) The Vale of Glamorgan Census 2001. See http://www.statistics.gov.uk/sensus2001/ pyramids/pages/00pd.asp for further details (accessed 01/09/2007).

Orme JAC (2007) Performance of Tidal Stream Turbines. PhD thesis, Swansea University.

PMSS (Project Management Support Services) (2006) Wales Marine Energy Site Selection, Rev 4. PMSS, Romsey.

Rhie CM and Chow WL (1983) Numerical study of the turbulent flow past an airfoil. AIAA Journal 21(11): 1525-1532.

SDC (Sustainable Development Commission) (2007) Tidal Power in the UK. SDC, London.

Stapleton CM, Wyer MD, Kay D et al. (2007) Fate and transport of particles in estuaries, volume IV: numerical modelling 
for bathing water enterococci estimation in the Severn Estuary. Environment Agency, London, report SC000002/ SR4.

Uncles RJ (1984) Hydrodynamics of the Bristol Channel. Marine Pollution Bulletin 15(2): 47-53.

Van Doormaal JP and Raithby G (1984) Enhancements of the Simple method for predicting incompressible fluid flows. Numerical Heat Transfer 7(2): 147-163.

WAG (Welsh Assembly Government) (2004) Interim Marine Aggregates Dredging Policy, Bristol Channel and Severn
Estuary. See http://new.wales.gov.uk/about/departments/ depc/epcpublications/PlanPubs/MPPW2001/

1469594?lang=en for further details (accessed 01/06/2007).

WAG (2008) Renewable Energy Route Map for Wales. WAG, Cardiff.

Yang L, Lin B and Falconer RA (2008) Modelling enteric bacteria levels in coastal and estuarine waters. Proceedings of the Institution of Civil Engineers, Engineering and Computational Mechanics 161(4): 179-186.

\section{What do you think?}

To discuss this paper, please email up to 500 words to the editor at journals@ice.org.uk. Your contribution will be forwarded to the author(s) for a reply and, if considered appropriate by the editorial panel, will be published as a discussion in a future issue of the journal.

Proceedings journals rely entirely on contributions sent in by civil engineering professionals, academics and students. Papers should be 2000-5000 words long (briefing papers should be 1000-2000 words long), with adequate illustrations and references. You can submit your paper online via www.icevirtuallibrary.com/content/journals, where you will also find detailed author guidelines. 